\title{
Moving from Multidisciplinary to Transdisciplinary Approach in Public Health through Educational Reforms
}

\author{
Sharma, $A .^{1} \&$ Zodpey, S. $^{2}$
}

\begin{abstract}
In order to tackle the grave health challenges which transcend both national boundaries and disciplinary paradigm, diverse workforce converging from multidisciplinary backgrounds is paramount. Given the range of feeder disciplines that contributes to public health, not much focus is given to cultivate the transdisciplinary element in the health workforce training and practice. It necessitates multifaceted efforts which can be achieved through on job cultivation, self-motivation and educational approach. This article emphasizes the essence of multidisciplinarity and urges for a shift to transdisciplinarity in public health through educational reforms. There are several challenges confronting public health education (PHE) in India. Gaps in health systems connectivity, pedagogic skills and faculty development, competency driven curriculum, career pathways for trained public health professionals and making PHE more multidisciplinary ought to be addressed. To advance a transdisciplinary approach through an educational lens, a multipronged strategy is proposed with reforms in admissions criteria, curriculum and competencies, faculty development, educational resources and assessment. Curricula should be capable of developing transdisciplinary and cross cutting competencies through competency driven education. Attempts should be directed in incorporating a transdisciplinary thinking in designing educational resources with the faculty coming from diverse backgrounds to make the teaching more comprehensive. A transdisciplinary public health education is a tool to create a transdisciplinary public health workforce which can bring a paradigm shift in the education of health professionals.
\end{abstract}

Key Words: Multidisciplinarity, Transdisciplinarity, Public Health Education, India

\section{Background}

C.E.A. Winslow (1920), one of the leading figures in public health, characterized public health as "the science and art of disease prevention, prolonging life, and promoting health and well-being through organized community effort for the sanitation of the environment, the control of communicable infections, the organization of medical and nursing services for the early diagnosis and prevention of disease, the education of the individual in personal health and the development of the social machinery to assure everyone a standard of living adequate for the maintenance or improvement of health".

${ }^{1}$ Senior Program Officer-Academic Programs,

Public Health Foundation of India, New Delhi.

${ }^{2}$ Vice President - Academics,

Public Health Foundation of India, New Delhi.

Corresponding Author:

Professor Sanjay Zodpey, Vice-President-Academics, Public Health Foundation of India,

Plot No. 47, Sec 44, Gurgaon-122002, Haryana, India

Email:sanjay.zodpey@phfi.org
The Institute of Medicine's landmark 1988 definition of public health provides an additional insight: "Public health is what we, as a society, do collectively to assure the conditions in which people can be healthy" (Childress et al., 2002). Where the definition and practice of public health has evolved over time, the complexity of public health issues has remained constant.

Glaring gaps and inequities in health persist both within and between countries, underscoring our collective failure to share the dramatic health advances equitably. At the same time, fresh health challenges such as new infectious, environmental, and behavioural risks, at a time of rapid demographic and epidemiological transitions, threaten health security of all (Frenk et al., 2010). To address these challenges, which transcend national boundaries and disciplinary paradigms (Evans et al., 2002), we ought to have an adroit and diverse workforce converging from multidisciplinary backgrounds. Public health problems require a multidisciplinary approach through engagement of diverse disciplines and breaking of professional silos. 
This paper emphasizes on the centrality of multidisciplinarity in public health and need to move from a multidisciplinary to transdisciplinary approach in public health through educational reforms.

\section{Multidisciplinary, Interdisciplinary and Transdisciplinary approaches to Public Health}

The recent Lancet Commission report on "Health professionals for a new century: transforming education to strengthen health systems in an interdependent world" further emphasised the importance of multidisciplinary, interdisciplinary and transdisciplinary education that breaks down professional silos while enhancing collaborative and non-hierarchical relationships in effective teams (Frenk et al., 2010). Terms such as "multidisciplinary", "interdisciplinary", and "transdisciplinary" have been used to denote efforts that involve several disciplines. However, these terms are ambiguously defined and often used interchangeably - a condition, Leathard (1994) described as a "terminological quagmire". Choi and Pak (2006) elucidate that the "Multidisciplinary approach draws on knowledge from different disciplines but stays within their boundaries. Interdisciplinary approach analyses, synthesizes and harmonizes links between disciplines into a coordinated and coherent whole. Transdisciplinary approach integrates the natural, social and health sciences in a humanities context, and transcends their traditional boundaries. The three terms refer to the involvement of multiple disciplines to varying degrees on the same continuum."

Thus, these three approaches form the underlying principles to provide different perspectives on problems and thus tackling complexities and encouraging innovations. However, the importance of these approaches for finding solutions to public health problems is still not well described. It would not be wrong to say that public health is inherently multidisciplinary, not only by philosophy but also by practice, and that its centrality is vital to the advancement and promotion of public health which reaches beyond the confines of individual disciplines.

The "Calcutta Declaration" adopted in 1999 at the Regional Conference on Public Health in South-East Asia, promoted public health as a discipline and, more importantly, emphasized its significance as a multidisciplinary endeavour to meet the health needs of people and thereby an essential requirement for national development (WHO, 2000). It also stated that in addition to addressing the challenges posed by ill-health and promoting positive health, public health should also address issues related to poverty, equity, ethics, quality, social justice, environment, community development and globalization. The WHO Commission on Social Determinants of Health (CSDH) also underlined the role that 'beyond health' measures play in ensuring and sustaining good health (CSDH, 2008). This broad scope of the public health mission needs an increasingly multidisciplinary workforce comprising of an array of public health professionals (Box 1). This also means integration of different academic disciplinary perspectives, with more interaction and fusion. The past few years have seen a growing interest in transdisciplinary approach across academic disciplines. Lancet and $\mathrm{WHO}$ have also recommended that a core curriculum should adopt transdisciplinary and multi-school approaches and instil a culture of lifelong learning.

\section{Who is a Public Health Professional?}

The Institute of Medicine has described a public health professional as a person educated in public health or a related discipline who is employed to improve health through a population focus (Hernandez et al., 2003). Colligating this construct, a cluster of public health professionals comes from diverse professions ranging from a public health physicians, researchers, and administrators to demographers, epidemiologists, social scientists, nutritionists, occupational health experts to public health geneticists, environmental toxicologists, food safety experts, town planners among others (Box 1).

Koo and Miner (2010) state that "Public health professionals support the public health mission in multiple ways, from educating those at risk about ways to prevent disease, to inspecting restaurants, to tracking down sexual contacts of a person with a sexually transmitted disease, to identifying patterns of disease and conducting epidemiologic investigations to identify risk factors, and to working with legislators to draft policy for smoke-free work environments." These multidisciplinary professionals thus contribute to the field through practice, education and training, research, program and policy development and advocacy at different levels of the health care delivery system and work together to address the health needs of communities. 


\section{Box 1: Who is a Public Health Professional?}

Public Health Physician, Public Health Specialist, Public Health Researcher, Public Health Practitioner, Public Health Administrator, Public Health Leader, Policy Analyst, Demographer, Epidemiologist, Entomologist, Bio-Statistician, Nutritionist, Public Health Engineer, Social Scientist, Behavioural Scientist, Anthropologist, Health Promoter, Health Communication Specialist, Occupational Health Specialist, Environmental Health Specialist, Health Manager, Program Manager, Health System Manager, Program Evaluator, Monitoring And Evaluation Specialist, Hospital Administrator, Veterinary Physician, Data Manager, Health Economist, Public Health Lawyer, Health Journalist, Industrial Hygienist, Public Health Nurse, Occupational Health Nurse, Human Rights Specialist, Community Dentist, Public Health Analyst, Disease Specific Experts, Molecular Biologist, Public Health Microbiologist, Public Health Geneticist, Environmental Toxicologist, Food Safety Expert, Town Planner, Trade Expert

\section{Feeder Disciplines to Public Health}

However, the important question - can one discipline produce them? If this would have been true, then public health as a discipline wouldn't have come into existence. The answer is that public health is a fusion of many disciplines which is cross cutting and has been created through a range of feeder disciplines (Box 2). These people might enter the public health field at different stages of their career. Some enter immediately after graduation with or without academic training in the field of public health, whereas others enter as mid-career professionals, again with or without formal training in public health. Thus public health can be considered a discovered discipline as it is not a person's initial profession but a choice embraced later in one's career (Koo \& Miner. 2010).

Given the range of feeder disciplines that contributes to public health, the reality is that not much importance and focus is given to cultivate and enhance the multidisciplinarity element in the health workforce training and practice which leads to a sense of rigidity and lack of trust between individual professions.

The development of public health professionals and their capability to meaningfully engage communities in public health and work in multidisciplinary teams is as important as training them in technical skills. Unfortunately, the existing scenario depicts a grim picture. There is undue prominence and dominance of the medical profession over other professions and the mutual respect and valuing each other discipline is at times missing. Lack of trust between participating professions and focus on professional autonomy further adds to the dissonance. Here, it is apt to quote Rudolph Virchow, one of the great $19^{\text {th }}$ century physician on the important role the medical profession can play in leading this change "Should medicine ever fulfil its great ends, it must enter into the larger political and social life of our time, it must indicate the barriers which obstruct the normal completion of the life cycle and remove them. Should this ever come to pass, medicine, whatever it may then be, will become the common good of all."

\section{Box 2: Feeder disciplines to Public Health}

Medicine, Nursing, Pharmacy, Social Sciences, Behavioural Sciences, Anthropology, Economics, Social Work, Basic Sciences, Veterinary Sciences, Demography, Epidemiology, Bio-Statistics, Data Management, Engineering, Technology, Informatics, Policy, Management, Public Administration, Nutrition, Law, Ethics, Human Rights, Occupational Health, Environmental Sciences, Health Promotion, Communication, Media, Journalism, Industrial Hygiene, Entomology, Microbiology, Dentistry, Genetics, Molecular Biology, Biotechnology, Toxicology, Town Planning / Urban Design, Agriculture, Transport, Trade, Commerce

Advancing Transdisciplinary Approach in Public Health through Educational Reforms

Advancing and strategizing transdisciplinarity requires multifaceted efforts which can be achieved through on job cultivation, selfmotivation and educational approach. The public health workforce comes from geographically dispersed multisector spectrum working in government, non-government, 
community based organizations etc., it becomes imperative to promote on-job cultivation bearing a multidisciplinary approach. After all, the education of this public health workforce should occur not only in academic settings, leading to a formal degree, but also in diverse on-the-job settings (Koo \& Miner 2010). Furthermore, one should be self-motivated, driven and committed to adapt working in multidisciplinary teams and embrace a group having a wide range of people from different backgrounds.

Deliberating on the Public Health Education (PHE) in India, historically, PHE has been offered through medical colleges as part of undergraduate (MBBS) curriculum and hands on experience during internship. Currently, there are 412 medical colleges in India which produce 52,225 medical graduates every year (MCl, 2014). The Departments of Preventive and Social Medicine/Community Medicine (PSM/CM) in medical colleges also provide postgraduate education in public health in the form of MD (PSM/CM), Diploma in Public Health (DPH) and Diploma in Community Medicine (DCM).

There are a total of 218 medical colleges which offer MD (PSM/CM) with an annual intake capacity of 740 . Likewise, 45 medical institutions offer DPH to a batch size of 151 students and 6 colleges run DCM with annual intake capacity of 11 students. In addition to these traditional programs, some of the medical colleges/institutions run following specialized courses for medical graduates with limited annual intake capacity: MD (Community Health Administration), MD (Hospital Administration), Masters in Hospital Administration, MD (Tropical Medicine), MD (Maternity and Child Health) and PhD (Hospital Administration), Diploma in Hospital Administration, Diploma in Health Education and Diploma in Industrial Health. Moreover, few institutions in the country offer Diplomat of National Board (DNB) in Family Medicine, Social and Preventive Medicine, Maternal and Child Health, Health Administration including Hospital Administration and Field Epidemiology courses (Sharma et al., 2014). However looking beyond the statistics, these postgraduate courses are available only for medical graduates and are taught by faculty with a medical background. Currently, PHE in India is at a critical juncture with a conscious shift at establishing public health schools outside the realm of medical colleges. Taking cognizance of the fact that public health is a multidisciplinary science, PHE in India is being offered in few institutions for both medical and nonmedical graduates over the past two decades. Some of them offer core public health programs (Masters in Public Health [MPH]) and some of them offer specialized courses (MPH with tracks/specialization). At present, a total of 35 institutions offer MPH programs in India with an annual intake capacity of 931 candidates. Additionally, some institutions have launched specialized courses in public health related disciplines. These courses include: Masters and diploma programs in health and hospital management/administration, epidemiology, health economics and healthcare financing, biostatistics and data management, public health nutrition etc. (Sharma \& Zodpey, 2013).

At the same time, there are several challenges surrounding PHE in India viz. health systems connectivity, pedagogic skills and faculty development, competency driven curriculum, accreditation of institutions and programs, career pathways for trained public health professionals. How to make PHE more multidisciplinary, relevant and tailor made to India's needs ought to be addressed. Ultimately, Public Health Education that is irrelevant to national health priorities and divorced from public health practice is useless and constitutes a lost opportunity (Tangcharoensathien \& Prakongsai, 2007).

The current complexity of public health problems requires professionals to seek ways of working across professional boundaries which can create a greater impact on the health of the people than they can make by working independently. To advance and propagate a transdisciplinary approach through an educational lens, a multipronged strategy is being proposed putting forth reforms in admissions criteria, curriculum and competencies, faculty development, educational resources and assessment.

Medical and non-medical graduates in various disciplines ranging from medicine, nursing, dentistry, occupational and physical therapy, complementary medical fields such as Ayurveda, Yoga and Naturopathy, Unani, Siddha and Homoeopathy (AYUSH), pharmacy, management, social sciences, anthropology, economics, demography, social work, behavioural sciences, nutrition, statistics, biological sciences, basic sciences, law to engineering, technology, informatics, biotechnology, veterinary sciences, environmental sciences, genetics, entomology to agriculture, communication, media, journalism, commerce among others are eligible to pursue $\mathrm{MPH}$ 
programs. And thus, greater advocacy is required to bring changes in existing policies on admissions to public health courses to enable students of all relevant disciplines e.g. economics, law, medicine, nursing, etc. to train in public health (Government of India \& WHO) to achieve the wide-ranging and evolving public health mission. It may be argued that better strategies emerge when public health professions bring together knowledge and experience from diverse perspectives to think about problems and generate solutions in new ways. Additionally, a thorough reflection is required for incorporating a transdisciplinary approach towards public health curriculum. Curricula should be capable of developing cross cutting competencies through competency driven education in public health professionals drawing strengths from basic sciences and inculcating the ability to deal with emergent issues such as ageing, genomics, informatics, global health, public policy, financing, strategy planning, among others.

At the same time, PHE quality and training needs to be enhanced. Recognizing that a multidisciplinary faculty is an indispensable ingredient in transcending the professional boundaries in public health, faculty recruitment challenges in quantity, quality and their right diverse mix need to be addressed appropriately. More specialized training programs for the faculty development should be initiated along with expanding the limited scope of $\mathrm{PhD}$ in public health and doctoral public health (DrPH) programs. A conscious effort should be made in developing and fostering a culture of respecting colleagues from different disciplines and sharing faculty resources and building long term partnerships. Attempts should also be directed in facilitating and incorporating transdisciplinary thinking in designing and conceptualizing educational resources to make the teaching and education more comprehensive and holistic which at present is a lacunae in public health education. Giving due weightage and underlining the multidisciplinary assessment can also go be one of the parameters in heralding a new change.

\section{Conclusion}

Most public health challenges are multifaceted and cannot be addressed effectively with simple, one-dimensional solutions. Blending flavours of different professions rather than individual ones is the need of the hour. Time has come to move from multidisciplinary to transdisciplinary to positively impact public health problems. A transdisciplinary public health education is a tool to create a transdisciplinary public health workforce which can bring a paradigm shift in the education of health professionals. As Abraham Maslow popularly phrased that - If you have a hammer everything will start to look like a nail (Maslow, 1966) i.e. if we would learn only one specific discipline very deep, we would try finding solution to every problem with that one discipline we have learnt rather than solving it by bringing in learnings from all the disciplines. Thus, in order to bridge the gaps and confront existing and emerging public health challenges, we need to find answers to complexities from multiple disciplines and fields and therefore a transdisciplinary approach may be an important vehicle in ushering in a new cadre of public health professionals.

\section{References}

Childress, J.F., Faden, R.R., Gaare, R.D., Gostin, L.O., Kahn, J., Bonnie, R.J., Kass, N.E., Mastroianni, A.C., Moreno, J.D. \& Nieburg, P. (2002) Public health ethics: mapping the terrain, The Journal of Law, Medicine \& Ethics, 30, 2, pp. $170-178$.

Choi, B.C.K. \& Pak A.W.P. (2006) Multidisciplinarity, Interdisciplinarity and Transdisciplinarity in health research, services, education and policy: 1. Definitions, objectives, and evidence of effectiveness, Clinical and Investigative Medicine, 29, 6, pp. 351-364.

CSDH (2008) Closing the gap in a generation: health equity through action on the social determinants of health, Final Report of the Commission on Social Determinants of Health, Geneva: World Health Organization.

Evans, D. \& Dowling, S. (2002) Developing a multidisciplinary public health specialist workforce: training implications of current UK policy. Journal of Epidemiology \& Community Health, 56, pp. 744-747.

Frenk, J, Chen, L, Bhutta, Z, A, Cohen, J, Crisp, N, Evans, T, Fineberg, H., Garcia, P., Ke, Y., Kelley, P. \& Kistnasamy, B. (2010) Health professionals for a new century: Transforming education to strengthen health systems in an interdependent world, Lancet, 376, pp.19231958.

Hernandez, L.M., Rosenstock, L. \& Gebbie, K. editors. (2003) Who will keep the public healthy?: educating public health professionals for the 21st century, Washington: National Academies Press.

Koo, D. \& Miner, K. (2010) Outcome-Based Workforce Development and Education in Public Health. Annual Review of Public Health, 31:253-269. 
Leathard, A. (1994) Going inter-professional: Working together for health and welfare, London: Psychology Press.

Maslow, A.H. (1966) The Psychology of Science: A Reconnaissance, Chicago: Gateway Editions, pp. 15. Available from: http://en.wikipedia.org /wiki/Law_of_the_instrument [Accessed March $\left.5^{\text {th }}, 2014\right]$.

Medical Council of India: Available from: http://www.mciindia.org/InformationDesk/Colleg esCoursesSearch.aspx. [Accessed March 3rd 2014].

$\mathrm{MoH}$, Government of India and WHO. (2009) Report on National Consultation on Public Health Workforce in India. New Delhi: p. 2.

Public Health in South-East Asia in the $21^{\text {st }}$ Century (2002) Report and Recommendations of the Regional Conference, New Delhi: World Health Organization Regional Office for South-East Asia (SEARO).
Sharma, A, Zodpey, S. \& Batra, B. (2014) Engagement of national board of examinations in strengthening public health education in India: Present landscape, opportunities and future directions, Indian Journal of Public Health, 58, pp. 34-39.

Sharma, A. \& Zodpey, S. P. (2013) Transforming public health education in India through networking and collaborations: Opportunities and challenges, Indian Journal of Public Health, 57, pp. $155-160$.

Tangcharoensathien, V. \& Prakongsai, P. (2007) Regional public health education: Current situation and challenges, Bulletin of the World Health Organization, 85 pp. 903-904.

Winslow, C.E.A. (1920) The untilled field of public health, Modern Medicine, 2, pp.183-191. 